\title{
Mechanisms of Density-Dependent Population Regulation in the Marine Copepod Amphiascoides sp. (Harpacticoida)*
}

\author{
I. Walker** \\ Department of Zoology, University of Dar-es-Salaam, Tanzania \\ and \\ Department of Zoology and Applied Entomology, Imperial College, London SW7, England
}

\begin{abstract}
Amphiascoides sp. was cultured in the laboratory for the first time. Culture method and data on its life cycle are given. Reproductive potential and behaviour (pairing incidence) were studied in relation to population density (i.e. to medium conditioned by a previously dense population) and in relation to food supply. It was found that: (1) conditioned medium reduces the number of ovisacs per female by reducing its fertile period and by extending the interval between release of successive pairs of ovisacs, older females being more susceptible to this inhibition; (2) conditioned medium causes partial sterilization (nonfertilization?) of eggs; (3) these effects are partly, but not completely, reversible when females are returned to fresh medium (delayed, density-dependent effects); (4) crowding itself, but not medium conditioned by crowding, reduces the number of eggs per ovisac; (5) ovisacs are not released in absence of food, and food supply triggers the release of ovisacs; (6) mating incidence is a function of food supply; (7) mating incidence is higher in groups than in isolated pairs; (8) repeated mating is necessary for sustained fertility; (9) infertile periods in females as a result of deprivation of food or males may be compensated for by extension of the normal (50-60 d) fertile period to maximally 80-100 d; (10) the generation period (nauplius to fertile adult) increased by $40 \%$ in the course of laboratory existence. These mechanisms of true population regulation via negative feedback are discussed in the light of the 'paradox of evolution under competition': resources are limited, yet, those genotypes that are getting more numerous than others (higher fitness) win the competition (= positive feedback).
\end{abstract}

\section{INTRODUCTION}

As earlier studies on population regulation in various invertebrates (Walker, 1967, 1975a, b; Walker and Williams, 1976), the present investigation results from the interest in the physical aspects of evolution. Under conditions of competition, that is when carrying capacity of a given factor is reached, a stable population has a growth rate of $r=0$ (Malthusian fitness), when each dying female is replaced by a single fertile daughter (Whitian fitness, $f=1$ ). In order to replace this population by a better genotype, the fitness of the new genotype would have to be larger than the one of the original genotype $\left(r^{\prime}>0 ; f^{\prime}>1\right)$. Hence, the population would grow hyperbolically as an ever increasing portion of individuals propagates with the fitness $I^{\prime}$ until all individuals are replaced by the new genotype.

\footnotetext{
- This study was in part funded by the Research and Publication Committee of the University of Dar-es-Salaam.

- Present address: Instituto Nacional de Pesquisas da Amazônia (INPA), 69000 Manaus, Amazonas, Brasil.
}

Yet, resources for this growth are not available, since the original population already operated at carrying capacity.

Evolution under competition thus represents the classical positive feedback, where the discrepancy between the 'sollwert' (population growth = zero) and the actual value is steadiliy increasing. Such populations fall into pathological oscillations (Wangersky and Cunningham, 1957; Walker, 1967) with absurd densities followed by mass decline after which few survivors build up the next cycle under conditions of surplus resources. Consequently, possible selection for a given genotype is periodically destroyed by random genetic drift. The conclusion is inevitable that orderly evolution under conditions of competition is possible only if the genetic increase in fitness is balanced by a reduction in phenotypic population fitness, while differential relative fitness between the genotypes is preserved. This necessitates continuous correction of reproduction and/or emigration in relation to space and resources via negative feedback mechanisms. 
Aquatic organisms offer the advantage that the two factors, density per space and density per food supply, can neatly be separated in the analysis. At high spatial population densities competition for food can never be excluded, even if the experimenter is under the impression that he provided surplus food; physical interference between individuals - such as jostling, fighting or perhaps nervous disturbance - may prevent certain individuals from spending enough time feeding. Regulation of density per area is probably effected by the excretion of pheromones. Thus, culture water previously densely populated can be filtered and reused to measure reproduction of single, well-fed individuals in such conditioned medium. The effect of food supply, on the other hand, can be assayed in fresh medium at low densities.

Earlier studies by these methods showed mutual inhibition of reproduction at high density and stimulation of reproduction at low density in the ciliates Paramaecium (Robertson, 1921), Tetrahymena (Stillwell, 1967) and Keronopsis (Walker, 1967) as well as in algae of the family Volvocaceae (Harris, 1971). Demonstration of similar population behaviour in a crustacean would add support to the hypothesis that density-dependent population regulation via negative feedback mechanisms is a general condition of living systems.

Amphiascoides sp. seemed to be the ideal experimental organism. It lives in the coastal waters of the Dar-es-Salaam area (Tanzania), apparently in great abundance, as it turned up regularly in the sea-water supply for the University's aquaria. It breeds profusely on small pieces of boiled vegetation, and laboratory populations survive indefinitely with a minimum of care. For a recent review on copepod cultivation consult 'Marine Ecology', Volume III: Kinne (1977).

The observations reported in this study fall into three phases which are separated by several years: preliminary observations were made in 1967 in Dar-esSalaam, several experimental series were carried out in London in 1971; the major part, however, was done from 1975-1976 in London. Hence, these experiments preceded the recent publications on population dynamics and ecology in various copepod groups (Gaudy and Guérin, 1977; Corkett and McLaren, 1978; Parrish and Wilson, 1978; Zurlini et al., 1978). These papers and some earlier ones will therefore be considered together with the results under 'Discussion' of this study.

\section{MATERIAL AND METHODS}

\section{Material}

The harpacticid was identified as Amphiascoides subdebilis Willey by Dr. W. Scheibel and Prof. W.
Noodt (Zoologisches Institut der Universität Kiel, Federal Republic of Germany) and as Amphiascoides cf neglectus (Norman and T. Scott) by Dr C. B. Coull (Belle Baruch Institute for Marine Biology, Columbia, S.C., USA). All three specialists feel that the taxonomy of this genus needs re-consideration and that this organism may be a new species.

\section{Methods}

The sea water supply for our aquaria, from which Amphiascoides sp. was isolated, and which also served for its cultures, came from the intertidal zone of Oyster Bay beach (Dar-es-Salaam) and of Mbegani beach (ca. $16 \mathrm{~km}$ from Dar-es-Salaam).

The culture medium was fresh sea water which was passed through a Whatman paper filter and sterilized by heating for $10 \mathrm{~min}$ to just below boiling point. This treatment proved to be sufficient (Walker, $1975 a$, b) to avoid contamination by micro-organisms.

Food was prepared by boiling pieces of lettuce leaves for $10 \mathrm{~min}$ in sea water and later supending them in cold, sterilized sea water. Glass Petri dishes (5 $\mathrm{cm} \varnothing$ for 1-20 individuals) and crystallizing dishes of 50 and $100 \mathrm{ml}$ for larger numbers of copepods were used for culture dishes. These were closed by glass covers in order to prevent evaporation. The culture dishes were washed and sterilized in distilled water and never came into contact with soap, detergents and chemicals.

Establishment of laboratory culture and routine maintenance. The culture was established in September 1966 with copepods from a single sea-water supply. In order to reassure myself that the harpacticids of later supplies were in fact the same species, as well as to obtain a reasonable genetic heterogeneity in the laboratory culture, I isolated in December 1967 single, juvenile individuals from the laboratory stock and from a recent sea-water supply. then paired immature partners from the two sources and later returned breeding females to the laboratory stock. Thus, either these mothers, or the males that fertilized them, originated from the new supply. With the exception of a few preliminary observations all data recorded in the following refer to this 'Laboratory Stock: This stock was pure insofar as there was no contamination by algae or protozoans. Furthermore, the culture water remained clear and showed no signs of bacterial contamination (in exceptional cases of accidental infection the respective cultures were eliminated). However, the detritus produced by the harpacticids may contain its own, intestinal micro-organisms. Thus, it cannot be affirmed that the laboratory stock was sterile. 
Ma in te na n ce. At approximately monthly intervals (depending on the density and condition of the culture) 50-100 individuals of all ages together with freshly released ovisacs were transferred by pipette into new culture dishes with $100 \mathrm{ml}$ of fresh medium and circa $2 \mathrm{~cm}^{2}$ of boiled lettuce. Within this period the culture may reach a density of 60-80 individuals per $1 \mathrm{ml}$. Amphiascoides works itself into the tissue of the leaf between epidermis and hypodermis and feeds on the parenchyma. New food was added whenever the former supply was near exhaustion. At weekly intervals the culture water was exchanged by mere decanting. The harpacticids stay preferably at the bottom of their glass dish; after vigorous stirring the light waste particles remain in suspension much longer than even eggs and nauplii. Thus, the old medium can be decanted and replaced by fresh. The level of the water was always marked in order to control evaporation in which case the level was restored by addition of distilled water. The cultures were kept at $23^{\circ} \pm 1 \mathrm{C}^{\circ}$ under natural night/day conditions.

Experimental cultures. Experimental animals were raised under low density conditions (50-100 per $100 \mathrm{ml}$ medium) with surplus food if not otherwise indicated. Conditioned medium was prepared in order to test the effect of high density on single or small groups of experimental animals. To this end a high density stock culture was left for 7-10 days without water exchange. Then, its medium was decanted and filtered first through a Whatman papier filter and then through a sintered glass filter with ultra fine pores together with $1 / 3$ of fresh medium. This purified and somewhat diluted old medium is referred to as 'conditioned medium'. In all tests, experimental and control animals came from the same culture, the conditioned medium from the same dish for all replicates, and the control medium consisted of fresh medium filtered by both methods as the conditioned medium. Conditioned medium and control medium came invariably from the same sea-water supply.

A-, B-, C-cultures. From May 1975 to
January 1976 three different culture regimes were maintained in three isolated breeding stocks

A-culture was kept at low density; in the extreme the density before renewal reached $15 \pm 5$ individuals of all ages per $1 \mathrm{ml}$, usually it stayed far below that; maintenance as described for the laboratory stock.

B - c u l t u r e was kept at low density as A, but the culture water consisted invariably of conditioned medium; this was prepared from the 'Laboratory Stock' culture as described above. Routine maintenance as described for the laboratory stock.

C - c u l t u re density was not regulated and routine maintenance as described for laboratory stock; thus, the density oscillated between low and extreme values, and consequently, so did the condition of the medium

\section{RESULTS}

\section{Normal Development}

A number of observations between 1966 and 1969 in Dar-es-Salaam (Table 1) showed that 4 moults at daily intervals brought the nauplius to the copepodite stage and that 6 further moults resulted in the adult. Deviations from this pattern were the exception and occurred more often during the later stages of development. Pairing and formation of ovisacs took place within $48 \mathrm{~h}$ after the last moult. The ovisacs were released within 1-3 $d$ after their appearance and the nauplii hatched within $24 \mathrm{~h}$. Copulation was invariably preceded by 'pair formation': the male attaches itself with its antennae to the tail furca of the female. Pairs remained joined for many hours. During this period repeated copulation took place, however, it is uncertain, whether each copulation was accompanied by renewed insemination. The sex ratio remained in the vicinity of $1: 1$ throughout. It was never determined by detailed counts, however, when raising a cohort of animals of equal age, one could rely on obtaining approximately

Table 1. Amphiascoides sp. Phases of development (range in days within which all individuals reach the respective stage)

\begin{tabular}{|c|c|c|c|c|c|c|c|}
\hline \multirow[t]{2}{*}{ Years and place } & \multicolumn{3}{|c|}{ Total number of } & \multicolumn{4}{|c|}{$\begin{array}{c}\text { Development } \\
\text { (days after day zero) }\end{array}$} \\
\hline & Tests & Replicates & Individuals & Day zero & $\begin{array}{l}\text { Meta- } \\
\text { morphosis }\end{array}$ & Adult & $\begin{array}{c}\text { First } \\
\text { ovisacs }\end{array}$ \\
\hline $1966-1969$ & & & & Nauplius & & & \\
\hline Dar-es-Salaam & 8 & 22 & 300 & $1^{\text {st }}$ stage & $3-6$ & $9-13$ & $11-16$ \\
\hline $1971-1975$ & & & & Nauplius & & & \\
\hline London & 6 & 12 & 120 & $1^{\text {st }}$ stage & $6-9$ & $14-19$ & $18-28$ \\
\hline
\end{tabular}


half the number of breeding pairs. In a few cases longevity was determined: the mean life span was circa 4 months while the oldest individuals reached 160 days (Table 7). Pairing behaviour extended over the whole life span, whereas production of ovisacs ceased considerably earlier, depending on conditions of nutrition and fertilization (see pp. 215 and 216). New ovisacs were usually formed within $24 \mathrm{~h}$ after release of the former pair.

Later observations in London showed the curious fact that the generation period (nauplius to first reproduction) had increased by about $40 \%$ (Table 1 ). One possible reason is the changed diurnal rhythm, long day/short day in London as against equatorial conditions in Dar-es-Salaam; however, this aspect was not investigated. The culture temperature was not involved as it was the same in both places.

\section{Effects of Conditioned Medium on Production of Ovisacs}

Data of three preliminary tests in Dar-es-Salaam (1969) showed that young, breeding females produced $46 \%$ less ovisacs in conditioned medium than in fresh medium (38 experimental females, 42 controls; observation period $=8-15$ days). The nature of this reduction was analysed in more detail in 1971 and 1975/76 in London.

\section{Tests from 1971}

Three test series were carried out with 10-12 experimental animals each and with the same number of controls. Young, mated females with their first ovisacs were isolated singly into $8 \mathrm{ml}$ Petri dishes with medium and food. During 18 days, ovisacs formed and released were noted daily. The females were kept in well-fed condition throughout. The 31 controls produced a mean of $4.71 \pm 1.22$ pairs of ovisacs per female at average intervals of $2.37 \pm 1.32$ days, whereas the 31 experimental females in conditioned medium produced only $3.13 \pm 1.28$ pairs of sacs at intervals of $3.39 \pm 1.41$ days $\left(t\right.$-test, $\left.P_{\text {ovs }}<0.05 ; P_{\text {days }}<0.05\right)$. The histograms from which these means are derived are shown in Figure 1. Conditioned medium has two separate effects: it extends the interval between the release of successive ovisacs and it reduces the number of ovisacs produced. As the observation was carried on until the experimental females had ceased to reproduce, the reduction of ovisacs per female is not the result of the extension of the period between successive pairs of ovisacs; the experimental females had enough time to produce whatever they were capable of.

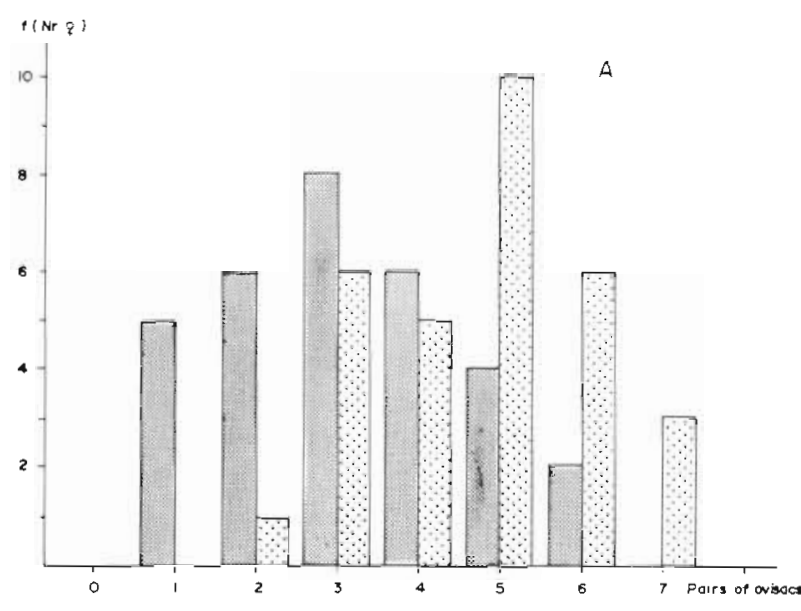

B

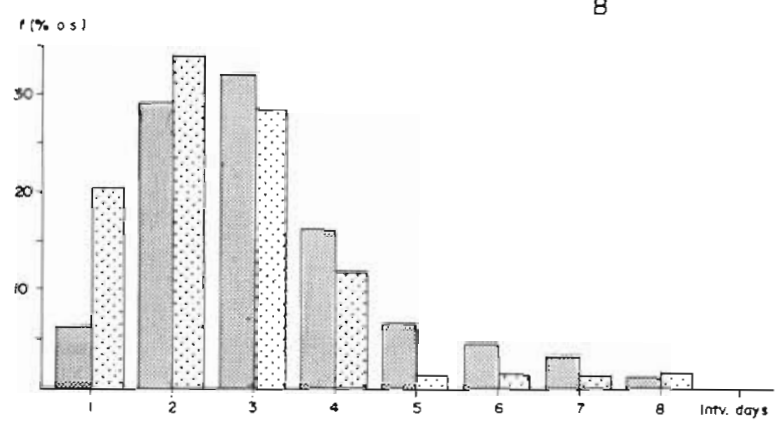

Fig. 1. Amphiascoides sp. Production of ovisacs in conditioned medium (31 experimental females, dark columns) and in fresh medium (31 control females, light columns). A: frequency of females [f (Nr. 9 )] producing various numbers of ovisacs. B: Percent ovisacs [f $(\%$ o.s. $)]$ released at certain intervals (intv. days) between successive pairs of ovisacs

Considering only the first of the three tests: of 59 second and further pairs of ovisacs produced (by experimental and control females), 55 appeared within less than $24 \mathrm{~h}$ after the release of the former pair. Periods of more than one day between release of successive ovisacs are thus characterized by the presence of ovisacs with delayed release, and not by delayed oogenesis and absence of eggs. The data of the second and third tests show a similar pattern, but are not presented in detail.

Continuation of test 3 : The females of the third test (Sept. 1971) were subject to further observation; 9 experimental and 10 control females lived sufficiently long so that the end of their reproductive period could be ascertained. After the initial 18 days of observation test and control females were divided into two groups each, one transferred into fresh medium and one into conditioned medium. Males were added to allow for renewed mating, and the harpacticids were kept in well-fed condition over their whole life span. Reproductive period and production of ovisacs are shown in 
Table 2. Amphiascoides sp. Reproduction in fresh and conditioned medium, 1971

\begin{tabular}{|c|c|c|c|c|c|}
\hline \multirow{5}{*}{ 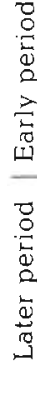 } & Medium: & \multicolumn{2}{|c|}{ Conditioned } & \multicolumn{2}{|c|}{ Fresh } \\
\hline & $\begin{array}{l}\text { Females tested (fertilized, } 2-4 \text { d old) } \\
\text { Observation period (days) } \\
\text { Ovisacs per } 9 \text { and early period }\end{array}$ & & & & \\
\hline & Medium: & Conditioned & Fresh & Conditioned & Fresh \\
\hline & $\begin{array}{l}\text { Females from above ( } 0 \text { added) } \\
\text { Last ovisacs after the }\end{array}$ & $5\left(C_{1} C_{2}\right)$ & $4\left(\mathrm{C}_{1} \mathrm{~F}_{2}\right)$ & $4\left(F_{1} C_{2}\right)$ & $5\left(F_{1} F_{2}\right)$ \\
\hline & $\begin{array}{l}\text { number of further days given } \\
\text { Ovisacs per } q \text { and later period }\end{array}$ & $\begin{array}{c}14 \mathrm{~d} \\
0.6 \\
\text { (sterile) }\end{array}$ & $\begin{array}{l}42 \mathrm{~d} \\
8.5\end{array}$ & $\begin{array}{c}33 \mathrm{~d} \\
4.8\end{array}$ & $\begin{array}{l}63 \mathrm{~d} \\
12.6\end{array}$ \\
\hline
\end{tabular}

Table 2. The results are summarized as follows: (1) Conditioned medium has an immediate repressive effect on the production of ovisacs. (2) Conditioned medium has a permanent effect on the production of ovisacs and on the reproductive period: conditioned, repressed females, when returned to fresh medium, do not recover their full reproductive potential. (3) The later phases of reproduction (i.e. older females) are much more susceptible to the inhibition by conditioned medium.

Developmental period: The above-mentioned effects could be the result of mere unspecific pollution in conditioned water. In this case we would also expect a delay of growth and differentiation in the offspring when raised in conditioned medium. However, 8 nauplii of the F1F2 females from Test 3 (above), raised in conditioned medium, reached metamorphosis and adult age at the same time as 8 control siblings in fresh sea water (mean of 7.7 days to metamorphosis and 20.3 days to adult in conditioned medium; controls 7.5 days and 19.9 days, respectively).
Tests from 1975/76: The A, B, C-series

Effect of conditioned medium on fertility ( T a b l e 3). Test animals of the three cultures (p. 211) were transferred into conditioned medium and the same number of controls were observed in fresh medium. From the C-culture two categories of harpacticids were assessed: (1) first breeders which came directly from a one-month-old, very high density culture, which, as far as may be told (p. 210), was nevertheless well fed; (2) individuals raised under low-density conditions as usual for test animals. This second category is directly comparable with the three tests from 1971 (Table 2, Fig. 1); the same conclusions apply to all groups in the $A, B$, and C-series: conditioned medium significantly reduces the number of ovisacs produced.

I had noticed on several occasions that in the Bculture and in any high-density culture an unusual number of eggs did not hatch, apparently their proteins coagulated, and they turned into a milky, opaque white, whereas fertile eggs are silvery and almost

Table 3. Amphiascoides sp. Reproduction in fresh and conditioned medium, 1976

\begin{tabular}{|c|c|c|c|c|c|c|}
\hline $\begin{array}{c}\text { Type } \\
\text { of test } \\
\text { individual }\end{array}$ & Medium & $\begin{array}{l}\text { Tests of } \\
10 \text { pairs }\end{array}$ & $\begin{array}{l}\text { Number of ovisacs } \\
\text { produced per } \\
1099 \text { in } 40 \text { days }\end{array}$ & $\begin{array}{c}\% \\
\text { hatched }\end{array}$ & $\begin{array}{l}\text { Fertile } \\
\text { periods (days } \\
\text { of adult age) }\end{array}$ & $\begin{array}{c}\mathrm{F}_{1} \text { (total } \\
\text { produced per } \\
1099 \text { ) }\end{array}$ \\
\hline $\mathrm{C}_{9}{ }^{\text {hd }}$ & Fresh & 3 & $\begin{array}{c}75 \\
\mathrm{P}<0.01\end{array}$ & $\begin{array}{c}75.6 \\
P<0.0025\end{array}$ & $35-40$ & 148 \\
\hline $\mathrm{C}_{9}^{\text {hd }}$ & Conditioned & 3 & 54 & 49.0 & $30-35$ & 34 \\
\hline $\mathrm{C}_{9}{ }^{\mathrm{ld}}$ & Fresh & 1 & $\begin{array}{c}128 \\
\mathrm{P}<0.01\end{array}$ & $\begin{array}{c}93.2 \\
\mathrm{P}<0.025\end{array}$ & $50-55$ & 615 \\
\hline $\mathrm{C}_{9}{ }^{1 d}$ & Conditioned & 1 & 90 & 75.9 & $50-55$ & 324 \\
\hline$A_{9}$ & Fresh & 2 & $\begin{array}{c}137 \\
\mathrm{P}<0.01\end{array}$ & $\begin{array}{c}84.3 \\
\mathrm{P}<0.025\end{array}$ & $40-45$ & 571 \\
\hline$A_{9}$ & Conditioned & 2 & 111 & 72.3 & $50-55$ & 350 \\
\hline $\mathrm{B}_{9}$ & Fresh & 2 & $\begin{array}{c}98 \\
P<0.01\end{array}$ & $\begin{array}{c}70.0 \\
P<0.01\end{array}$ & $30-35$ & 410 \\
\hline $\mathrm{B}_{9}$ & Conditioned & 2 & 67 & 54.5 & $25-30$ & 175 \\
\hline
\end{tabular}


transparent. Table 3 shows that sterilization of part of the eggs is a regular consequence of conditioned medium, the percent of eggs from which nauplii hatched is significantly reduced. The two effects, reduction of eggs and partial sterilization of the eggs actually produced, result in a drastic cut-down of the $F_{1}$ from females which breed in conditioned medium. These may be regarded as 'immediate effects' because females raised in fresh water at low densities also show them when transferred into high-density conditioned medium ( $\mathrm{C}^{\text {ld }}$ and $\mathrm{A}$ ). $\mathrm{C}^{\text {hd }}$ and $\mathrm{B}$-females were raised in conditioned medium and set into fresh water to breed. They produced fewer eggs and a higher percent of sterile eggs than controls raised in fresh medium ( $P<0.01$ and $<0.025$, respectively). Referring to a single generation period, these are long-term, irreversible effects.

B-females, although raised in conditioned medium, were nevertheless kept at low numbers during growth; in contrast, $\mathrm{C}^{\text {hd }}$-individuals were exposed to high density, with large numbers of animals jostling for the same food supply, as well as to conditioned medium. This may explain the fact that $C^{\text {hd }}$-females produced considerably fewer ovisacs than B-females, both, in fresh and conditioned medium $(p<0.05)$. Furthermore, counts of the number of eggs per ovisac show that $\mathrm{C}^{\mathrm{hD}}$-females also produce smaller sacs: these contain on the average 11.3 eggs ( 74 ovisacs counted) as compared with 13.1 in B-females (45 sacs counted of females raised in conditioned water; $t$-test, $P<0.001$ ). The ovisacs of A-females contain 14.1 eggs (all these numbers refer to single sacs, not to the pair). Reduction of eggs per ovisac is thus largely due to the density of animals on the same food supply and not to conditioned medium.

Lastly, growth and differentiation of Amphiascoides $\mathrm{sp}$. in conditioned medium and at high density seems to reduce their fertile period by about $40 \%\left(\mathrm{C}^{\text {hd }}\right.$ and $\mathrm{B}-$ females as compared with $\mathrm{C}^{\text {ld }}$ and A-females). The tests were not designed to determine the fertile period, these data are a mere by-product of the daily counts of ovisacs, hence, they do not lend themselves to statisti- cal evaluation. There is one remarkable observation, though, with regard to breeding periods: if we compare these data with test No 3 from September 1971 (Table 2), we find that the F1F2 females bred over a period of 81 days. This is a further indication that the laboratory stocks changed their life cycle in the course of years (p. 212).

The combined effects of conditioned medium and high density - which are: reduction of number of ovisacs, reduction of fertile eggs per ovisac, extension of interval between release of successive pairs of ovisacs and reduction of fertile period - result in a total offspring of 3.4 per single $C^{\text {hd }}$-mother. Considering that the sex ratio is $1: 1$, and that the reduced fertile period allows for little overlap of generations, this brings fitness to the vicinity of 1 . These data explain the repeated, but quite casual, observations that an aged, dense population cannot be substantially increased by abundant feeding and by the occasional, partial water changes which are necessary to remove excessive waste products.

Effect of conditioned medium on the re le as e of ovis acs. Delayed release of ovisacs in conditioned medium, as shown by the three tests in 1971 was also verified in the A, B, and C-cultures. Young, breeding females carrying ovisacs were transferred directly from low-density cultures into observation dishes with conditioned and fresh water, respectively. During three subsequent days the number (not pairs) of ovisacs were noted. Table 4 gives the data per 50 females or, as each female initially carried one pair of ovisacs, in percent of ovisacs. C-females release their sacs more readily than either A $\left(P<0.0025, X^{2}\right.$ test) or $\mathrm{B}(P<0.001)$; more sacs are released on the first day after transfer. A-individuals in fresh medium and $\mathrm{B}$-individuals in conditioned medium represent the normal breeding conditions of these stocks; release of ovisacs is certainly delayed in the B-culture $(P<0.0025)$. A-females, when brought into conditioned medium, behave like B-females; however, $B$-females in fresh medium are even more delayed than when in their accustomed (conditioned) medium: $21 \%$ less

Table 4. Amphiascoides sp. Release of ovisacs in fresh and conditioned medium

\begin{tabular}{|c|c|c|c|c|c|c|}
\hline \multicolumn{3}{|c|}{ Experimental females } & \multicolumn{4}{|c|}{ Ovisacs released per $50 Q Q$} \\
\hline Type & $\begin{array}{l}\text { Number of } \% ? \text { per } \\
\text { number of tests }\end{array}$ & Medium & $1^{\text {st }}$ day & $2^{\text {nd }} \mathrm{ddy}$ & $3^{\text {rd }}$ day & $\begin{array}{l}\text { Total } \\
\text { released }\end{array}$ \\
\hline $\mathrm{C}_{2,3,4}$ & $60 / 3$ & Fresh & 57 & 22 & 15 & 94 \\
\hline $\begin{array}{l}A_{2,3.4} \\
A_{2,3}\end{array}$ & $\begin{array}{r}120 / 6 \\
40 / 2\end{array}$ & $\begin{array}{c}\text { Fresh } \\
\text { Conditioned }\end{array}$ & $\begin{array}{l}40 \\
16\end{array}$ & $\begin{array}{l}35 \\
40\end{array}$ & $\begin{array}{l}13 \\
29\end{array}$ & $\begin{array}{l}88 \\
85\end{array}$ \\
\hline $\begin{array}{l}\mathrm{B}_{2,3} \\
\mathrm{~B}_{2.3 .4}\end{array}$ & $\begin{array}{l}40 / 2 \\
90 / 6\end{array}$ & $\begin{array}{c}\text { Fresh } \\
\text { Conditioned }\end{array}$ & $\begin{array}{l}23 \\
22\end{array}$ & $\begin{array}{l}30 \\
48\end{array}$ & $\begin{array}{l}16 \\
20\end{array}$ & $\begin{array}{l}69 \\
90\end{array}$ \\
\hline
\end{tabular}




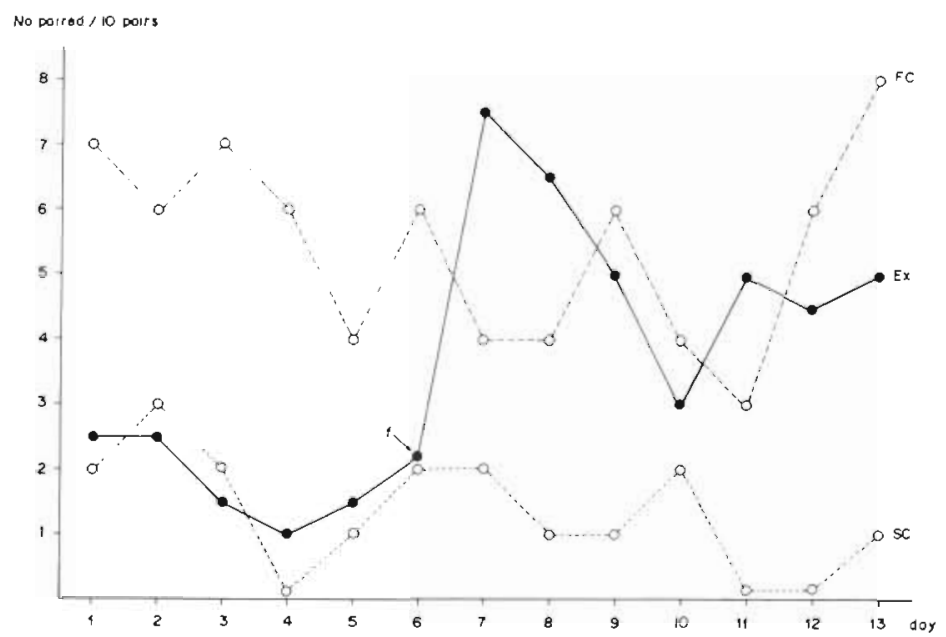

Fig. 2. Amphiascoides sp. Dynamics of daily pairing incidence as a function of food supply over an observation period of $13 \mathrm{~d}$. FC: food control, one group of 10 pairs fed during whole observation period; SC: starvation control, one group of 10 pairs starved during whole observation period; EX: experimentals, means of 2 groups of 10 pairs each, fed only on the 6th d (f) and thereafter. Difference between any 2 curves: $P<0.01$ (sequence test)

ovisacs are released within the three days. This shows again the long-term effect of conditioned medium on reproduction which cannot be reversed by bringing the females back into fresh medium. As nauplii hatch upon release of the ovisacs, and as new sacs can only be formed after release of the former pair, delayed release of ovisacs means delayed development with a respective increase of the generation period and decrease of fitness.

\section{Effect of Food Supply on the Release of Ovisacs and on the Incidence of Mating}

\section{Effect of food supply on the release of ovisacs}

Young, experimental females carrying ovisacs were isolated in groups of 10 on day zero and then starved for a definite number of days; the number of ovisacs released was noted every day. After this period the females were fed and observed for an equal period after feeding; again, the number of released ovisacs was noted. All harpacticids were kept in fresh medium. Controls were fed during both periods. The results are shown in Table 5. It may be stated almost categorically that ovisacs are not released in the absence of food; $85-100 \%$ of the females detach their eggs only when they chance upon a food source. Females which are starved for 5 and more days seem to resorb part of their eggs, ovisacs become smaller and in cases disappear altogether. Another explanation may be that eggs rupture and that their content disperses into the medium, or that females begin to eat their eggs as reported by Marshall and Orr (1964) for Calanus; however, I never noticed anything to this effect. The controls produce their second and third pairs of sacs during the observation period whereas the experimental females are unable to recover their reproductive potential in the prolonged post-feeding period of $4-7 \mathrm{~d}$. That a fresh food supply actually triggers the release of ovisacs is particularly evident in the case of single-day deprivation of food, none of the females released its sacs during this day but most did on the second upon feeding, whilst the controls released them on the first day. Futhermore, $75 \%$ of the females, which were starved for $4 \mathrm{~d}$ released their ovisacs within $24 \mathrm{~h}$ after food was provided again (not shown in Table 5).

Table 5. Amphiascoides sp. Release of ovisacs as a function of food supply

\begin{tabular}{|c|c|c|c|c|c|c|c|c|c|}
\hline \multicolumn{2}{|c|}{$\begin{array}{l}\text { Observed periods } \\
\text { (days) }\end{array}$} & \multicolumn{2}{|c|}{$\begin{array}{c}\text { Number of } 9 \% \\
\text { observed }\end{array}$} & \multicolumn{3}{|c|}{$\begin{array}{c}\text { Experimentals: } \\
\text { ovisacs released per } 10 \% \%\end{array}$} & \multicolumn{3}{|c|}{$\begin{array}{c}\text { Controls: } \\
\text { ovisacs released per } 10 \% ?\end{array}$} \\
\hline $\begin{array}{l}\text { before } \\
\text { feeding }\end{array}$ & $\begin{array}{c}\text { after } \\
\text { feeding }\end{array}$ & $\begin{array}{l}\text { Experi- } \\
\text { mentals: }\end{array}$ & Controls & $\begin{array}{l}\text { before } \\
\text { feeding }\end{array}$ & $\begin{array}{c}\text { after } \\
\text { feeding }\end{array}$ & Total & $\begin{array}{l}\text { before } \\
\text { feeding }\end{array}$ & $\begin{array}{c}\text { after } \\
\text { feeding }\end{array}$ & Total \\
\hline 1 & 1 & 40 & 40 & 0 & 11.50 & 11.50 & 9.75 & 3.25 & 13.00 \\
\hline 4 & 4 & 30 & 60 & 2.67 & 19.67 & 22.34 & 18.00 & 10.17 & 28.17 \\
\hline 5 & 5 & 20 & 10 & 3.00 & 11.50 & 14.50 & 14.00 & 25.00 & 39.00 \\
\hline 7 & 7 & 10 & 10 & 3.00 & 14.00 & 17.00 & 28.00 & 22.00 & 50.00 \\
\hline
\end{tabular}


Effect of food supply on the incidence of mating

In any mass culture of Amphiascoides sp. a fraction of individuals finds itself in pairs, the males being attached by their antennae to the tail furca of the females. Addition of new food to a culture nearing the exhaustion of its previous food supply results in a sudden rise of the number of pairs; this, at least, is the impression one gets during routine maintenance of the cultures. To test the hypothesis that meeting with a food source triggers pairing behaviour, small groups of experimental animals were observed: during an initial period they were deprived of food; on the sixth day they were fed and kept well fed thereafter. Two groups served as control: one that was fed throughout (food control) and one that was starved throughout (starvation control). At $24 \mathrm{~h}$ intervals the number of pairs present was counted. The product between number of pairs observed (coupled + uncoupled condition) and number of observation days represents $100 \%$ of observation units. The sum of coupled pairs observed over all observation intervals (days) expressed as fraction of these $100 \%$ of observation units is defined as pairing incidence'. It may be interpreted as the $\%$ pairs present in paired condition on a single day, or as the $\%$ days a single pair was found coupled over a given observation period. Figure 2 leaves no doubt that discovery of a food source after a period of deprivation acts indeed as a pairing triggers. It is important, though, that even in a population in starving condition pairing incidence fluctuates around $10 \%$.

\section{Mating and Fertility}

Group effect on the incidence of pair formation

In order to determine the dynamic pattern of pair formation in more detail, single young pairs of copepods were isolated into $10-\mathrm{ml}$ Petri dishes with fresh medium and food. However, it was soon apparent, that these conditions did not match the high pairing incidence in mass cultures; isolated pairs remained in general separated. This was not due to a reduced probability of encounters between the sexes, because male and female spent most of their time on the small piece of lettuce leaf and hence, well within each other's sphere of perception. To detect a possible group effect on pairing incidence, single pairs, which had been observed for an initial period were subsequently grouped in 3-5 pairs and observed for a second period. Pairs kept in groups during both periods served as controls. The data of all similar tests are summarized in Table 6. Pairing is 5-7 times more intense in groups than in single pairs. Still, pairing incidence is $5 \%$ in single pairs and thus presumably ample to guarantee insemination.

\section{Pairing and fertility}

To understand pairing behaviour as a function of food supply and social structure we must know whether fertility is dependent on repeated mating. As Figure 3 shows, this is decidedly the case. The drop of fertility at the adult age of $15-25 \mathrm{~d}$ also occurs if females are provided with males during this period. This is evident from a series of observations not presented in further detail: in two groups of 20 and 10 pairs with a pairing incidence of $40-60 \%$, ovisac production was reduced to $1 / 3$ at this age and it ascended again into a minor peak later. Figure 3 shows that in females deprived of males fertility drops to zero and stays there. Yet, if supplied with males after prolonged periods of deprivation, already aged females produce belated peaks of fertility which partly compensate for the loss of reproduction in the earlier phase.

\section{Reproductive Period and Longevity}

The suspicion that reproductive losses due to limited deprivation of food and males might be compensated for by an extended fertile period appears justified if all data on fertile periods and longevity that became

Table 6. Amphiascoides sp. Group éffect on pairing incidence

\begin{tabular}{|c|c|c|c|}
\hline Experimental pairs & Number observed & $\begin{array}{l}\text { Total observation units } \\
\text { (pairs } \times \text { days): } 100 \%\end{array}$ & $\begin{array}{l}\text { Pairing incidence } \\
(\%)\end{array}$ \\
\hline $\begin{array}{l}\text { Single pairs during first } \\
\text { observation period }\end{array}$ & 32 & 263 & 5.3 \\
\hline $\begin{array}{l}\text { In groups of } 3-5 \text { pairs during } \\
\text { second observation period }\end{array}$ & Same pairs as above & 217 & 26.7 \\
\hline $\begin{array}{l}\text { Controls: In groups of } 5 \text { pairs } \\
\text { during } 1^{\text {st }} \text { and } 2^{\text {nd }} \text { period }\end{array}$ & 20 & 145 & 36.6 \\
\hline
\end{tabular}



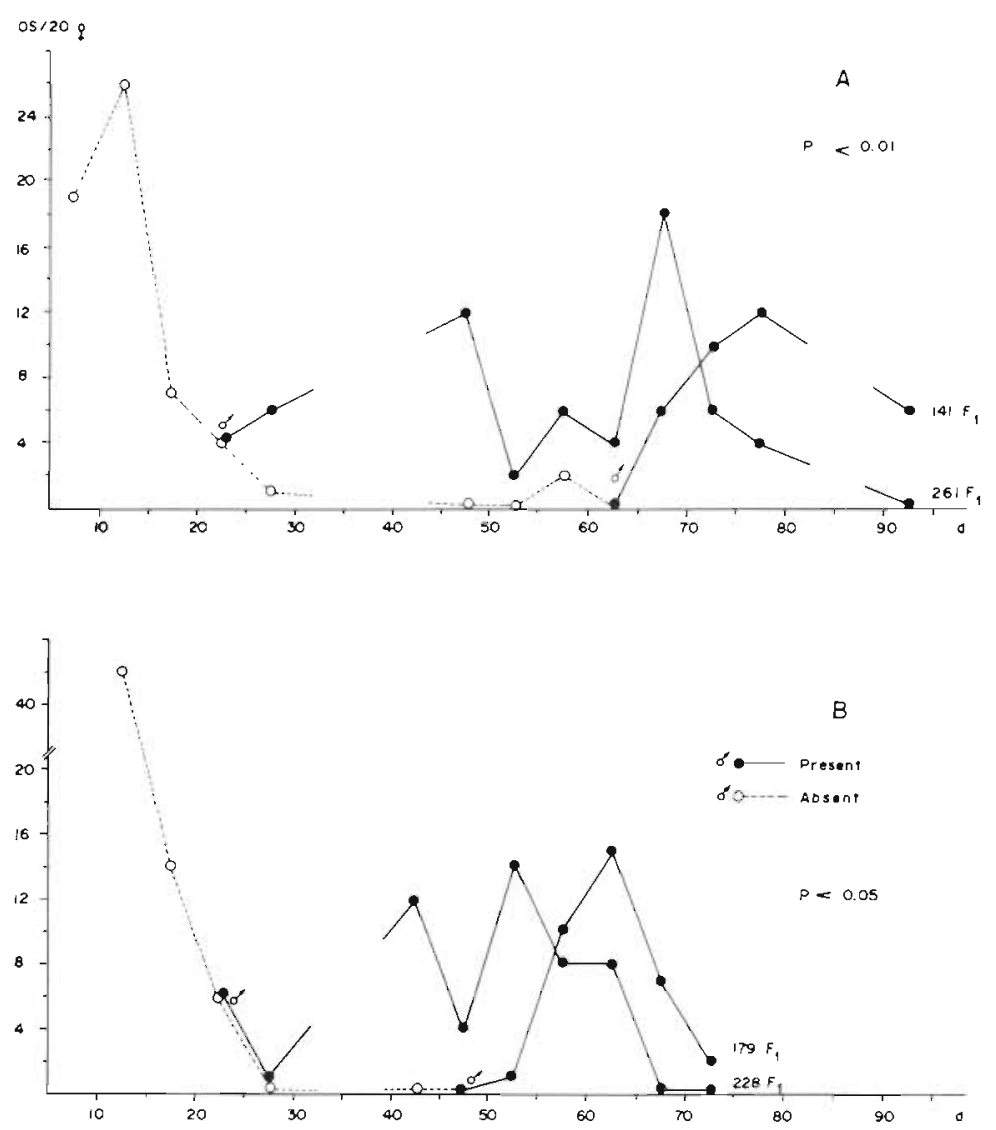

Fig. 3. Amphiascoides sp. Fertilization and fertility. Two series (A, B), each with 2 groups of 20 initially fertilized females. Males added later after various male-less periods. OS/20 $\delta$ : total number of ovisacs produced by 20 females within successive 5 -d periods. d: adult age in days of the females. $F_{1}=$ total offspring produced after age of $20 \mathrm{~d}$. $\mathrm{P}=$ significance for difference between the 2 groups (sequence test)

available in the course of time are compiled in a table (Table 7). None of the observation series had been designed to determine the fertile period, hence the data refer really only to the one, longest producing female within the respective group. Still, it is evident that under laboratory conditions at least, the fertile period is much shorter than the mean longevity of approximately 4 months. Females provided with males and food throughout seem to spend half of their life span in sterile old age, whereas females deprived for limited periods seem to prolong their fertile period. The simplest explanation would be that females have a limited supply of oocytes and use these according to availability of food and mates.

As to deprivation of food a few explanations are in place here: in absence of fresh food, Amphiascoides sp. feeds on its own faeces. This became evident in females which had been fed with yeast dyed with methyl blue to mark them individually for a limited period (their intestine becoming blue). Such females were put together singly with a group of starved, undyed individuals which, in turn, acquired blue intestines and produced blue faeces. Deprivation of food does thus not mean absolute starvation, at least for some time. Still, in females starved for more than $15 \mathrm{~d}$ the ovaries become transparent as all protein disappears, the harpacticids turn more and more transparent and the normally vigorous movements slacken off.

\section{DISCUSSION}

Table 8 summarizes some of the more recent biological data on various copepod species bred in the laboratory (for review see 'Marine Ecology' volume III: Kinne, 1977). The data of Gaudy and Guérin (1977) include the various Tisbe species of Battaglia's laboratory ${ }^{*}$. We find that the sex ratio fluctuates around $1: 1$ in harpacticoids and calanoids alike, which points to a common genetic mechanism of sex determination. A

\footnotetext{
- Battaglia (1957); Battaglia (1970); Parise and Lazzaretto (1966); Volkmann-Rocco and Fava (1969); Volkmann-Rocco and Battaglia (1972).
} 
deviation in favour of males at high population densities, as Heinle (1970) reports for Acartia tonsa, was never observed in Amphiascoides sp. Breeding difficulties arose sporadically in the A-and B-cultures, which were kept perpetually at relatively low densities and thus were subject to intense inbreeding. In such abnormal cultures pairing incidence and females with ovisacs became infrequent or ceased altogether However, the sex ratio was not determined. Still, the observation would suggest that Amphiascoides sp., a harpacticoid as Tisbe, suffers modification of the sex ratio in favour of males as a result of inbreeding, as Battaglia (1964) has reported for Tisbe.

Taking the various breeding temperatures into

Table 7. Amphiascoides sp. Reproductive period and longevity

\begin{tabular}{|c|c|c|c|c|c|c|c|}
\hline \multirow[t]{2}{*}{ Year } & \multicolumn{2}{|c|}{ Experimental animals } & \multicolumn{2}{|c|}{ Deprived of } & \multirow{2}{*}{$\begin{array}{l}\text { Last offspring } \\
\text { within group } \\
\text { after } n^{\circ} \text { days }\end{array}$} & \multicolumn{2}{|c|}{$\begin{array}{c}\text { Longevity } \\
\text { dead at adult age (d }\end{array}$} \\
\hline & & & (no days) & (n $\mathrm{n}^{\circ}$ days) & & $50 \%$ & $100 \%$ \\
\hline 1975 & 10 pairs & $12-18$ & 0 & 0 & 56 & 132 & 160 \\
\hline 1975 & 6 pairs & $2-7$ & 0 & 0 & 50 & - & - \\
\hline 1975 & 5 pairs & $2-7$ & 0 & 0 & 62 & - & - \\
\hline 1975 & $30 \%$ (fert) & $2-7$ & & 0 & 19 & - & - \\
\hline 1975 & 30 q (fert) & $10-20$ & Throughout & 0 & 40 & - & - \\
\hline 1971 & $7 q 9$ (fert) & $2-4$ & & 0 & 31 & - & - \\
\hline 1975 & 20 ㅇ (fert) & $10-20$ & 28 & 0 & 76 & - & - \\
\hline 1975 & 20 우 (fert) & $10-20$ & 15 & 0 & 71 & - & - \\
\hline 1971 & 5 의 (fert) & $2-4$ & 18 & 0 & 84 & 121 & 144 \\
\hline 1971 & $6 \%$ (fert) & $2-4$ & 18 & 0 & 71 & - & - \\
\hline 1975 & 8 pairs & $?$ & 0 & 28 & 74 & 107 & 133 \\
\hline 1975 & 6 pairs & $2-7$ & 0 & 50 & 75 & 62 & 153 \\
\hline 1975 & 10 pairs & $12-1.8$ & 0 & 65 & $\begin{array}{l}111 \\
\text { (sterile eggs) }\end{array}$ & 80 & 160 \\
\hline
\end{tabular}

Table 8. Comparison of biological data from various copepod species bred in the laboratory. Numbers in brackets: data obtained by inference, not by direct tests

\begin{tabular}{|c|c|c|c|c|c|c|c|c|}
\hline Species and authors & $\begin{array}{l}\text { Longevity } \\
\text { (inclusive } \\
\text { development) }\end{array}$ & $\begin{array}{l}\text { Duration of } \\
\text { develop- } \\
\text { ment }\end{array}$ & $\begin{array}{l}\text { Fertile } \\
\text { period }\end{array}$ & $\begin{array}{c}\text { Pairs of } \\
\text { ovisacs } \\
\text { per female }\end{array}$ & $\begin{array}{l}\text { Eggs per } \\
\text { pair of } \\
\text { ovisacs }\end{array}$ & $\begin{array}{c}\text { Eggs } \\
\text { per } \\
\text { female }\end{array}$ & $\begin{array}{l}F_{1} \text { per } \\
\text { female }\end{array}$ & $\begin{array}{l}\text { Sex ratio } \\
(\% / \% \\
\text { females })\end{array}$ \\
\hline $\begin{array}{l}\text { Tisbe holothuriae } \\
\text { Gaudy and } \\
\text { Guérin (1977) }\end{array}$ & $\begin{array}{c}23.6-33.4 \mathrm{~d} \\
19^{\circ} \mathrm{C}\end{array}$ & $12 \mathrm{~d}$ & $6.5-10.5 \mathrm{~d}$ & $3.7-5.1$ & & & $188-310$ & $40-58$ \\
\hline $\begin{array}{l}8 \text { Tisbe species } \\
\text { Gaudy and } \\
\text { Guérin (1977) }\end{array}$ & $\begin{array}{c}23.6-81.4 \mathrm{~d} \\
18^{\circ}-19^{\circ} \mathrm{C}\end{array}$ & $12 \mathrm{~d}$ & $10.5-23 \mathrm{~d}$ & $5-9$ & $31-78$ & & $128-513$ & $33-60$ \\
\hline $\begin{array}{l}\text { Euterpina acutifrons } \\
\text { Zurlini et al. (1978) }\end{array}$ & & $\begin{array}{l}10-12 \mathrm{~d} \\
18^{\circ} \mathrm{C}\end{array}$ & $19-40 \mathrm{~d}$ & 12.5 & $16-26$ & & 295 & 39.8 \\
\hline $\begin{array}{l}\text { Amphiascoides sp. } \\
\text { (present paper) }\end{array}$ & $\begin{array}{c}131 \text { d until } 50 \% \text { dead } \\
170 \text { d maximum } \\
23^{\circ} \mathrm{C}\end{array}$ & $9-19 d$ & $\begin{array}{c}50 \mathrm{~d} \\
(80-100 \\
\text { maximum) }\end{array}$ & 10.5 & $\begin{array}{c}23-28 \\
\text { (young } \\
\text { females) }\end{array}$ & $(150-300)$ & $(61-100)$ & $(50)$ \\
\hline $\begin{array}{l}\text { Acartia tonsa } \\
\text { Parrish and } \\
\text { Wilson }(1978)\end{array}$ & $\begin{array}{l}\text { exclusive development: } \\
\qquad \begin{array}{c}26-43 \mathrm{~d} \\
18^{\circ} \mathrm{C}\end{array}\end{array}$ & & $\begin{array}{l}39 \mathrm{~d} \\
\text { maximum }\end{array}$ & & & $450-1596$ & & \\
\hline $\begin{array}{l}\text { Rhincalanus nasutus } \\
\text { Calanus helgolandicus } \\
\text { Mullin and Brooks (1970 }\end{array}$ & & $\begin{array}{l}23 \mathrm{~d} \\
15^{\circ} \mathrm{C}\end{array}$ & & & & & & $\sim 50$ \\
\hline $\begin{array}{l}\text { Pseudocalanus } \\
\text { Corkett and } \\
\text { McLaren (1978) }\end{array}$ & $\begin{array}{l}>100 \mathrm{~d} \\
6^{\circ}-14^{\circ} \mathrm{C}\end{array}$ & $46-63 \mathrm{~d}$ & $5-43 d$ & $3-16$ & 25 & & & $\sim 50$ \\
\hline
\end{tabular}


account, development periods show little differences. Battaglia (1970) reports 10 moults from egg to adult in Tisbe. This coincides with Amphiascoides sp.; however, Tisbe has 5 nauplius and 5 copepodite stages, whereas Amphiascoides has 4 and 6, respectively.

Values of reproduction are of the same order of magnitude within the harpacticoids, and are relatively low as compared with the pelagic Acartia tonsa.

However, Amphiascoides differs radically from other harpacticoids in longevity and in fertile period. As roughly $50 \%$ of ovisacs are produced during the first month of its longevity, adult Amphiascoides survive 4-5 of their own generations. Theoretically, a female would still be alive, when some 50 000-100 000 of its female descendents populate the area. It can afford to lose most of its $F_{1}$ and $F_{2}$ and still produce a compensatory $F_{1}$. More important still, the enormous life span, the capacity to survive prolonged starvation and the flexibility of the reproductive period allow for regulation of reproduction in response to population density and availability of food and males. The data for Pseudocalanus (Corkett and McLaren, 1978) might suggest a similar pattern. Thus, they found that starved females lived up to $71 \mathrm{~d}$. However, these authors worked with very low temperatures as compared with the culture temperature of Amphiascoides sp., and the data are therefore not comparable on a physiological basis. Ecologically, though, the two species might command similar strategies, each within its own, natural temperature range.

A proper regulation mechanism must correct both, positive and negative deviations from a programmed output (= sollwert); overpopulation and underpopulation are to be avoided. Thereby, the sollwert is not a fixed value, but has different optima depending on the amount of food per area. Such regulative mechanisms can only be evaluated in relation to the biology of the species.

As Amphiascoides sp. is new to research, the possible relationships between its biology and ecology, outlined in what follows, are partly hypothetical.

It is certain that firstly, Amphiascoides sp. lives in the tidal zone with its sand flats, coral reefs and tidal pools, where food sources are patchy and where accidental dispersal by waves and currents must be frequent; secondly, Amphiascoides sp. is essentially a plant-detritus feeder; and thirdly both sexes are freely mobile, and continued breeding needs repeated insemination. Consequently, the harpacticid may have to solve the following problems: to survive prolonged, foodless periods of passive disperal; to implant a colon-izing group in a food patch accidentally met with; to secure mates and to avoid over-exploitation of isolated habitats.

In free living organisms the highest possible fre- quency of chance encounters between males and females is $50 \%$ at a sex ratio of $1: 1$. Continuous inbreeding in dense and stable groups would allow for devious sex ratios to develop, for example a reduction of males, while outbreeding opposes such deviation, firstly because a species which preserves the $1: 1$ ratio presumably has a higher breeding success, and secondly because recombination of genotypes is more intense within a mobile and more dispersed group; accidental aberrations would have little chance to accumulate, in other words, selection, as a result of relatedness, would be low (Hamilton, 1972). In Amphiascoides sp. pairing incidence is higher if harpacticids are in groups than if they are isolated in pairs, and patchy food distribution favours ephemeral group formation. This probably results in multiple insemination of a single female by various males, and thus in maximum genetic variation among the offspring of a single female. The tenacious pairing behaviour, in that males remain attached to females for many hours, ensures that many adults disperse in pairs. Longevity and the capacity to survive periods of starvation, together with the possibility of deferring fertile periods, favour the chances of dispersed individuals or pairs colonizing habitats accidentally encountered. The most efficient mechanism to this end is the formation and release of ovisacs. These are carried along and are ready to be released when a new egg supply is mature to form the next pair of sacs. Thus, during a fertile period, females have a reserve of mature eggs almost permanently, despite the fact that eggs can only be laid in discrete batches; the release is triggered by the finding of a food source. Hence, while the coincidence of harpacticid and food may be left to chance, the placement of the eggs is strictly coordinated with food availability; no eggs are wasted in unsuitable places.

This mode of oogenesis and embryogenesis is more complex than meets the eye insofar as hatching of the nauplii is correlated with the release of ovisacs. It is, in fact, almost a case of ovoviparity with all its maternal protection for the developing embryo. There is, in addition, the relation between number of eggs per ovisac and shortest interval between release of subsequent pairs of ovisacs. The opportunist would be expected to form smaller sacs at shorter intervals. In this respect it is interesting that the C-stock, which is oscillated through low and extreme densities, produced smaller, but more readily detachable ovisacs than the Stocks A and B, which were kept in more stable conditions.

All these mechanisms compensate underpopulation; they promote speedy colonization and enable a disturbed population to accelerate recovery.

Some of the very same mechanisms reduce popula- 
tion increase at high densities, such as retention of ovisacs in absence of food and in medium conditioned by high population density, together with delayed hatching of the $F_{1}$. In addition, there is the abbreviation of the reproductive period in females subject to high density with partial sterilization of their eggs. Combined with the non-lethal, but nevertheless delayed density-dependent effects (reduction of reproduction in the $F_{1}$ that developed under conditions of high density) Amphiascoides sp. approaches stability $(r \simeq 0)$ at conditions of extreme density; this occurs even in the absence of predation and accidential loss, both of which are undoubtedly high in nature. Thus, the reducing regulators seem to be more than adequate to prevent collapse of a population due to over-exploitation of the habitat. As long periods of isolation in closed water bodies are exceptional in the tidal zone, conditioning of the medium (supposedly by pheromones) may rather have the function of inducing active dispersal. Conditioning of the medium, intensified pairing when in groups and attachment of males to females for extended periods would then constitute an integrated mechanism of dispersal and crossbreeding as a function of local density.

In order to estimate the power of regulative mechanisms quantitatively, series of life tables at various densities in relation to food and water volume would be necessary, as well as the establishment of a dispersal function in relation to density. The range of $r$ values thus established would represent the capacity of phenotypic stress absorption by a species or population. The ideal population density would lie somewhere in the middle of tolerable limits where enhancing and reducing population regulation mechanisms function free of friction, causing the minimum of delayed effects. Such an approach would lead to a more realistic assessment of population dynamics than the tradition of calculating future population densities as a function of minor ripples in the infrastructure of reproductive chance and behaviour. Population models with constant reproductive rates are clearly of exclusive theoretical interest. With regard to the evolutionary prospects the situation is reversed: individual ripples of $r$-values in different genotypes determine the quality of genes which will be selected, whereas the regulated population stabilizes the level of competition and thus of the selection pressure, and thus prevents non-linear, qualitative switches in the genetic selection system (switches to aggression and defense or to mere drift as a result of population collapse for example).

One further point with regard to evolutionary prospects needs to be mentioned. Regulated reproduction and dispersal are the result of dynamic processes: more or fewer eggs are produced and dispatched earlier or later; development is more or less delayed; emigration is more or less intense. It had been shown in previous studies (Walker and Williams, 1976; Walker, 1979) that environmentally induced dynamic patterns will inevitably be fixed by irreversible accumulation of genetic effects if there is no active selection for their flexibility Thus, the extreme flexibility of Amphiascoides' reproductive, density-dependent behaviour indicates its selective value. Furthermore, the $A$ and $B$-stocks, kept at stable low and high densities, respectively, showed reasonably stable, specific reproductive patterns. These regimes lasted for 9 months only, and genetic loss of flexibility can hardly be expected in this short period. However, the different patterns indicate the long-term direction of a genetic change, if the same conditions were to continue. It is possible, furthermore, that the almost 10 years of laboratory breeding of the laboratory stock under comparatively high densities (as compared to natural conditions) led to the marked change of the life cycle (Table 1); in other words, extended developmental period (mathematically far more powerful than reduction of birth rate, Malthus, 1803; Rabinovich, 1968) and sterility during the later part of life may be laboratory artefacts in the process of genetic fixation. In this respect it is interesting that Corkett and McLaren (1978) obtained fertile ovisacs for $80 \mathrm{~d}$ from Pseudocalanus females collected in the sea, yet females raised in the laboratory had a maximum fertile period of only $43 \mathrm{~d}$ and remained sterile for up to $70 \mathrm{~d}$.

Acknowledgements. The author would like to thank Professor W. Noodt, Dr. W. Scheibel and Dr. C. B. Coull for the identification of Amphiascoides, Dr. P. Bayley and Dr. J. Rankin for reading the script and for helpful criticism, and Mrs. M. Trindade Lages for her help in preparing script and tables.

\section{LITERATURE CITED}

Battaglia, B. (1957). Richerche sul ciclo biologico di Tisbe gracilis ( $\mathrm{T}$ Scott), (Copepoda, Harpacticoida), studiato in condizioni di laboratorio. Archo Oceanogr. Limnol., 11, $29-46$.

Battaglia, B. (1964). Advances and problems of ecological genetics in marine animals. Int. Congr. Genet., (London), $11,451-463$

Battaglia, B. (1970). Cultivation of marine copepods for genetic and evolutionary research. Helgoländer wiss. Meeresunters., 20, 385-392.

Corkett, C. I. and McLaren, I. A. (1978). The biology of Pseudocalanus. In F. S. Russell and M. Yonge (Eds), Advances in Marine Biology, Vol. 15. Academic Press, London pp. 2-11.

Gaudy, R. and Guérin, J. P. (1977). Dynamique des populations de Tisbe holothuriae (Crustacea: Copepoda) en élévage sur trois régimes artificiels différents. Mar. Biol., 39, $137-145$ 
Hamilton, W D. (1972). Altruism and related phenomena, mainly in social insects. A. Rev. ecol. Syst., 3, 193-232.

Harris, D. O. (1971). A model system for the study of algae growth inhibitors. Arch. Protistenk., 113, 230-234.

Heinle, D. R. (1970). Population dynamics of exploited cultures of calanoid copepods. Helgoländer wiss. Meeresunters., 20, 360-372.

Kinne, O. (1977). Cultivation of animals. Research cultivation. In O. Kinne (Ed.), Marine Ecology, Vol. III, Cultivation, Part 2. Wiley, Chichester. pp. 579-1293.

Malthus, T. R. (1803). An Essay on Population, J. M. Dent and Sons Ltd., London. (repr 1966.)

Marshall, S. M. and Orr, A. P. (1964) Grazing by copepods in the sea. In D. T. Crips (Ed.), Grazing in Terrestrial and Marine Environments. Blackwell, Oxford. pp. 227-237.

Mullin, M. M. and Brooks, E. R. (1970). Growth and metabolism of two planctonic marine copepods as influenced by temperature and type of food. In J. H. Steele (Ed.), Marine Food Chains. Oliver and Boyd, Edinbourgh. pp. 74-95.

Parise, A. and Lazzaretto, I. (1966). Mizure di populazione sul copepode Tispe furcata (Baird) (Harpacticoida). Atti Memorie Accad patavina, 79, 1-11.

Parrish, K. K. and Wilson, D. F. (1978). Fecundity studies on Acartia tonsa (Copepoda: Calanoida) in standardized culture. Mar. Biol., 46, 65-81.

Rabinovich, J. E. (1968). Contribucion al estudio de la dinamica de poblaciones. Acta biol. Venez., 6, 68-81

Robertson, T. B. (1921). The influence of initial contiguity upon reproduction rate and the part played therein by the $\mathrm{X}$-factor in bacterized infusions which stimulate the multiplication of infusoria. Biochem. J, 15, 612-619.

Stillwell, R. H. (1967). Colpidium-produced RNA as a growth stimulant for Tetrahymena. J. Protozool., 14, 19-22.
Volkmann-Rocco, B. and Fava, G. (1969). Two sibling species of Tisbe (Copepoda, Harpacticoida): Tisbe reluctans and $T$. persimilis n. sp. Research on their morphology and population dynamics. Mar. Biol., 3, 159-164.

Volkmann-Rocco, B. and Battaglia B. (1972). A new case of sibling species in the genus Tisbe (Copepoda, Harpacticoida). In B. Battaglia (Ed.), Proceedings of the Fifth European Marine Biology Symposium. Piccin, Padova. pp. $67-80$.

Walker, I. (1967). Effect of population density on the viability and fecundity in Nasonia vitripennis. Ecology, 48 , $294-301$

Walker, I. (1975a). Density-dependent control of fission rates in the marine ciliate Keronopsis rubra Ehrenberg (Hypotricha, Oxytrichidae). J. Anim. Ecol., 44, 107-117.

Walker, I. (1975b). The effect of saline concentration on the fission rate in the marine ciliate Keronopsis rubra Ehrenberg (Hypotricha, Oxytrichidae). Revue suisse Zool., 82, 349-367.

Walker, I. (1979). The mechanical properties of the proteins determine the laws of evolutionary change. Acta biotheor., 28, 1-44.

Walker, I. and Williams, R. M. (1976). The evolution of the cooperative group. Acta biotheor., 25, 1-43.

Wangersky, P. J. and Cunningham, W. J. (1957). Time lags in population models. Cold Spring Harb. Symp. quant. Biol., 22, 329-339.

Zurlini, G., Ferrari, I. and Nassogne, A. (1978). Reproduction and growth of Euterpina acutifrons (Copepoda, Harpacticoida) under experimental conditions. Mar. Biol., 46, $59-64$. 